A.A.S. 4, I, 169-171 (2009)

\title{
INTERNATIONAL CONFERENCES
}

From 2009 the Actuarial Profession is pleased to publish, free of charge, in Annals of Actuarial Science, announcements of major international actuarial conferences.

Please email your announcements to Nicky Wilkinson, Journals Administrator at nicky.wilkinson@actuaries.org.uk

Please see over for details of the 6th Conference in Actuarial Science \& Finance on Samos, June 3-6, 2010. 


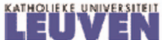

KATHOLIEKE

UNIVERSITEIT LEUVEN

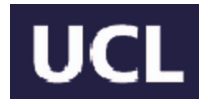

UNIVERSITÉ CATHOLIQUE DE LOUVAIN

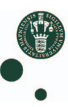

UNIVERSITY OF COPENHAGEN

\section{6th CONFERENCE IN ACTUARIAL SCIENCE \& FINANCE ON SAMOS, JUNE 3-6, 2010}

The Department of Statistics \& Actuarial - Financial Mathematics of University of the Aegean is pleased to host the 6th Samos Conference. Detailed information can be found on the web site:

\section{http://www.actuar.aegean.gr/samos2010/}

This event, jointly organized with the Katholieke Universiteit Leuven, the Université Catholique de Louvain and the Kobenhavns Universitet, provides a forum for state-of-the-art results in the area of actuarial science and finance. The meeting is open to people from Universities, Insurance Companies, Banks, Consulting Firms or Regulatory Authorities, interested in actuarial - financial mathematics.

\section{Topics:}

- Modelling Catastrophic Risks in Insurance and Finance (Chair: Holger Drees)

- Risk Measures in Non-Life Insurance and Portfolio Management (Chair: Zinovyi Landsman)

- Risk and Stochastic Control (Chair: Soeren Asmussen)

- Financial Risk Management (Chair: Thaleia Zariphopoulou)

- Modelling Dependence in Multivariate Risk (Chair: Gena Samorodnitsky)

- Decision Making in Life, Health and Pension Insurance (Chair: Mogens Steffensen)

A short course will be given before the conference (May 31 to June 2) under the title:

- Financial Modelling with Levy Processes, by Rama Cont - Columbia University, USA

\section{Invited Speakers:}

- Philippe Soulier - University Paris X, France

- Paul Embrechts - ETH Zurich, Switzerland

- Peter Glynn - Stanford University, USA

- Xunyu Zhou - Oxford University, United Kingdom

- Henrik Hult - KTH (Royal Institute of Technology), Sweden

- Erhan Bayraktar - University of Michigan, USA

- Seva Shneer - Eurnadom, The Netherlands 
Scientific Committee:
Albrecher Hansjoerg
Mikosch Thomas
Asmussen Soeren
Morettin Pedro
Cheliotis Dimitris
Ng Kai Wang
Drees Holger
PapaioanouTakis (Chair)
Foss Serguei
Samorodnitsky Gena
Gerber Hans
Steffensen Mogens
Goovaerts Marc
Teugels Jef
Konstantinides Dimitrios
Tang Qihe
Makov Udi
Zariphopoulou Thaleia
Marceau Etienne 